\title{
Efficacy, Effectiveness, Pragmatic Trials - Guidance on Terminology and the Advantages of Pragmatic Trials
}

\author{
Claudia M. Witt \\ Institute for Social Medicine, Epidemiology and Health Economics, Charité - University Medical Center, Berlin, Germany
}

Clinical research in complementary medicine focuses on a variety of different questions. For example, there are studies that determine the efficacy of a treatment compared to placebo in an experimental setting, whereas others evaluate the effectiveness of an additional treatment in a real-world setting. There is an ongoing discussion about the advantages and limitations of efficacy and effectiveness studies. The need for comparative effectiveness research (CER) is emphasised by the U.S. administration's decision to spend more than 1 billion USD for this research over the next 2 years with the aim to obtain information that helps clinicians and patients choose those options that best fit the individual patient's needs and preferences [1]. Although the methods of CER are not entirely new, the federal initiative supports research that is either more comprehensive - i.e., encompassing many more treatments and conditions, as well as more complete outcome measures - ore more relevant to real-world clinical decisions than traditional clinical research [2]. Such comparisons allow going beyond those between medication $\mathrm{A}$ and medication $\mathrm{B}$ or device A and device B. It is relevant to compare medications or devices with behavioural interventions, either alone or in conjunction with other approaches [3].

The difference between the term efficacy and the term effectiveness is not well known and there seems to be a grey area in the understanding of efficacy and effectiveness studies. This confusion can be seen in previous literature where for example both terms are used synonymously within one and the same study [4]. Therefore, I would like to explain both terms and, additionally, to outline the value of pragmatic trials for complementary and alternative medicine (CAM) using an example from acupuncture research.

\section{Efficacy and Effectiveness, Comparative Effectiveness}

'Efficacy' refers to 'the extent to which a specific intervention is beneficial under ideal conditions [5]. It primarily concen- trates on the causal effects of a treatment, e.g. by comparing it to a placebo. An 'efficacy trial' is typically considered an explanatory trial which is performed under experimental (ideal) conditions. For example, inclusion and exclusion criteria are used to select patients without co-morbidity and with excellent compliance.

'Effectiveness' is a 'measure of the extent to which a specific intervention when deployed in the field in routine circumstances does what it is intended to do for a specific population' [5]. In other words, 'effectiveness' reflects whether a treatment is beneficial under conditions close to routine care and effectiveness studies use a more 'pragmatic' approach. This means that inclusion and exclusion criteria are less narrow and the treatment protocol correlates more to a usual care situation.

\section{Pragmatic Trials}

Randomised trials can be explanatory or pragmatic. Trials designed to help choose between different options for care are called 'pragmatic'. Trials designed to test causal research hypotheses - for example, that an intervention causes a particular biological change are called 'explanatory' [6]. A pragmatic trial can be broadly defined as a randomised controlled trial, with the purpose to inform about decisions made in practice. They are designed to find out about how effective a treatment actually is in routine everyday practice and have relevance for complementary medicine [7]. The extension of the CONSORT statement is intended to improve reporting of such trials and focuses on applicability [8].

\section{Examples from Acupuncture Research}

For acupuncture, both efficacy and effectiveness studies are available. In one of our projects, efficacy and effectiveness studies were performed for the same diagnoses over a similar period of time [9]. Two study modules were performed:

\section{KARGER}

Fax +497614520714

Information@Karger.de

www.karger.com (c) 2009 S. Karger GmbH, Freiburg

Accessible online at:

www.karger.com/fok
Prof. Dr. Claudia M. Witt, MBA

Institut für Sozialmedizin, Epidemiologie und Gesundheitsökonomie

Charité - Universitätsmedizin Berlin

10098 Berlin, Germany

Tel. +49 30 450529-132, Fax -917

claudia.witt@charite.de 
Table 1. Key differences between explanatory and pragmatic trials - example from acupuncture research (adapted from the CONSORT extension for pragmatic trials [8])

\begin{tabular}{|c|c|c|}
\hline & $\begin{array}{l}\text { ART low back pain [12] } \\
\text { Explanatory trial on efficacy }\end{array}$ & $\begin{array}{l}\text { ARC low back pain }[13] \\
\text { Pragmatic trial on effectiveness }\end{array}$ \\
\hline Question & $\begin{array}{l}\text { [Efficacy - can the intervention work?] } \\
\text { Whether acupuncture was more efficacious in reducing pain } \\
\text { than sham acupuncture or no acupuncture in patients with } \\
\text { chronic low back pain. }\end{array}$ & $\begin{array}{l}\text { [Effectiveness - does the intervention work when used in } \\
\text { normal practice?] } \\
\text { Whether acupuncture, in addition to routine care among } \\
\text { patients with chronic low back pain, is more effective as } \\
\text { well as costs-effective, compared with routine care alone. }\end{array}$ \\
\hline Setting & $\begin{array}{l}\text { [Well resourced, 'ideal' setting] } \\
30 \text { well trained study centres in primary care were selected }\end{array}$ & $\begin{array}{l}\text { [Normal practice] } \\
3,486 \text { physicians in primary care }\end{array}$ \\
\hline Participants & $\begin{array}{l}\text { [Highly selected. Poorly adherent participants, and those with } \\
\text { conditions which might dilute the effect are often excluded] } \\
\text { Aged } 40-75 \text { years; clinical diagnosis of chronic low back } \\
\text { pain; disease duration }>6 \text { months; average pain intensity of } \\
\geq 40 \text { on a } 100 \text {-mm VAS during the previous } 7 \text { days; use of } \\
\text { oral non-steroidal anti-inflammatory drugs only for pain } \\
\text { treatment in the } 4 \text { weeks prior to treatment. In addition, } \\
12 \text { exclusion criteria. }\end{array}$ & $\begin{array}{l}\text { [Little or no selection beyond the clinical indication of } \\
\text { interest] } \\
\text { Aged } \geq 18 \text { years; clinical diagnosis of chronic low back pain } \\
\text { with disease duration }>6 \text { months. In addition, } 8 \text { exclusion } \\
\text { criteria. }\end{array}$ \\
\hline Intervention & $\begin{array}{l}\text { [Strictly enforced and adherence is monitored closely] } \\
\text { Semi-standardised acupuncture developed by an expert } \\
\text { consensus, } 12 \text { treatments, each } 30 \text { min duration over } 8 \text { weeks }\end{array}$ & $\begin{array}{l}\text { [Applied flexibly as it would be in normal practice] } \\
10-15 \text { treatments in } 3 \text { months; acupuncture points and } \\
\text { number of needles were decided on by the physician }\end{array}$ \\
\hline Outcomes & $\begin{array}{l}\text { [Often short term surrogates or process measures] } \\
\text { Visual analogue scale for pain }(0-100)\end{array}$ & $\begin{array}{l}\text { [Directly relevant to participants, funders, communities, } \\
\text { and healthcare practitioners] } \\
\text { Back function questionnaire (HFAQ) }\end{array}$ \\
\hline $\begin{array}{l}\text { Relevance to } \\
\text { practice }\end{array}$ & $\begin{array}{l}\text { [Indirect-little effort made to match design of trial to } \\
\text { decision making needs of those in usual setting in which } \\
\text { intervention will be implemented] } \\
\text { Indirect-patients and clinicians are highly selected and } \\
\text { it is not clear how widely applicable the results are for } \\
\text { clinical practice. }\end{array}$ & $\begin{array}{l}\text { [Direct - trial is designed to meet needs of those making } \\
\text { decisions about treatment options in setting in which } \\
\text { intervention will be implemented] } \\
\text { Direct - results reflect usual care and can be used for } \\
\text { decision making }\end{array}$ \\
\hline
\end{tabular}

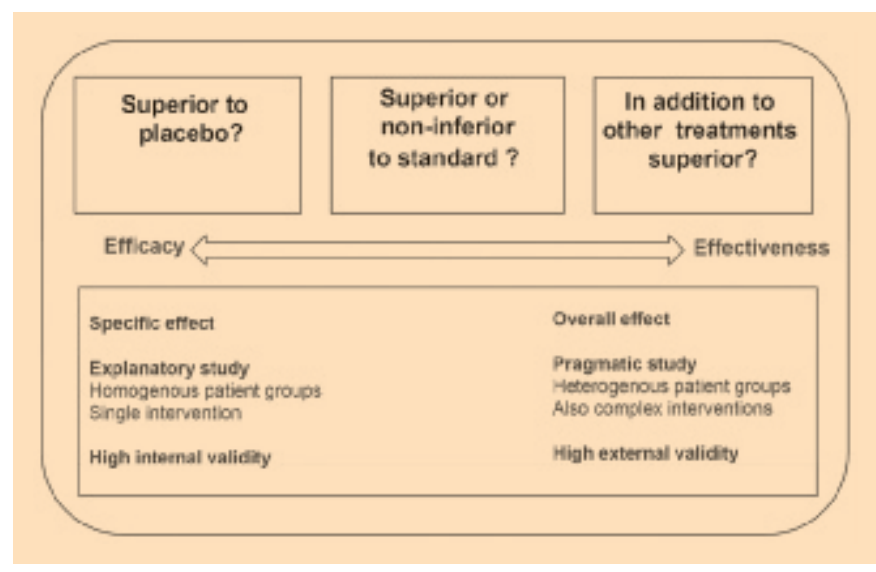

Fig. 1. The relationship between the research question and the corresponding study design.

one focusing on effectiveness (Acupuncture in Routine Care Study, ARC), and the other focusing on efficacy (Acupuncture Randomized Trial, ART). Both modules of the project also assessed low back pain, and these studies will serve as an example to demonstrate the difference between effectiveness and efficacy trials. Based on the CONSORT extension, table 1 displays the key differences between pragmatic and explanatory trials by showing the original terms (in brackets) of the CONSORT extension and the information from both trials.

The more pragmatic approach of the ARC study compared to the more explanatory approach of the ART study is clearly shown. An important point is that both studies, although being RCTs, answer different research questions. The focus of the ART study is on the acupuncture point specific effect whereas the ARC study evaluates the effectiveness of an additional acupuncture treatment in routine care. There are many research questions (fig. 1) and depending on the research question, a study should use a more explanatory or a more pragmatic design, which again has an impact on the internal and external validity of the study results.

\section{The Challenge of Whole Medical Systems}

In practice, CAM treatments are usually tailored to the individual patient, whereas in clinical studies they are mainly applied to all patients in a standardised manner. Some CAM 
treatments, for example naturopathy, Chinese medicine, Ayurveda or homeopathy, are classified as whole medical systems. The National Center for Complementary and Alternative Medicine (NCCAM) defines whole medical systems as systems that are built upon complete systems of theory and practice. Such systems have evolved prior and separate from the conventional medical approach [10]. Clinical research on whole medical systems is confronted with 2 major disadvantages: (1) a fragmentation of their treatment, and (2) interventions which follow a Western diagnostic approach. Pragmatic studies focusing on effectiveness and including additional aspects of the traditional diagnosis could help overcome these problems.

\section{Conclusion}

When discussing efficacy or effectiveness and the use of explanatory or pragmatic trials, their relevance for decision making has to be taken into account. This is not only a methodological issue, but also an ethical and political one. The core of this discussion is on the question as to whether the evidence for the specific effect, or the evidence that it works in usual care has more impact. Currently, efficacy studies including a placebo control are mainly used for decision making. This was the case in Germany in 2006, when the decision to fund certain acupuncture procedures was made. Yet, this focus on causality neglects the fact that it is problematic to generalise the results from efficacy studies. In the US, there is an increasing awareness of the limited information provided by results of explanatory randomised clinical trials for decisions about therapeutic alternatives as applied in actual practice [11].

For valid decision making on CAM, more clinical trials are required that reflect the situation in usual care and provide realistic benefit estimates for future health care.

\section{References}

1 Conway PH, Clancy C: Comparative-effectiveness research - implications of the Federal Coordinating Council's Report. N Engl J Med 2009;361:328-330.

2 Garber AM, Tunis SR: Does comparative-effectiveness research threaten personalized medicine? N Engl J Med 2009;360:1925-1927.

$>3$ Volpp KG, Das A: Comparative effectiveness - thinking beyond medication A versus medication B. N Engl J Med 2009;361:331-333.

$\checkmark 4$ Bäurle P, Suter A, Wormstall H: Safety and effectiveness of a traditional ginkgo fresh plant extract - results from a clinical trial. Forsch Komplementmed 2009;16:156-161.

5 Last J, Spasoff, RA, Harris S: A Dictionary of Epidemiology. Oxford, Oxford University Press, 2001.
6 Schwartz D, Lellouch J: Explanatory and pragmatic attitudes in therapeutical trials. J Chronic Dis 1967; 20:637-648.

7 MacPherson H: Pragmatic clinical trials. Complement Ther Med 2004;12:136-140.

$>8$ Zwarenstein M, Treweek S, Gagnier JJ, Altman DG, Tunis S, Haynes B, et al: Improving the reporting of pragmatic trials: an extension of the CONSORT statement. BMJ 2008;337:a2390.

$\checkmark$ Cummings M: Modellvorhaben Akupunktur - a summary of the ART, ARC and GERAC trials. Acupunct Med 2009;27:26-30.

10 National Center for Complementary and Alternative Medicine: What is CAM? nccam.nih.gov/health/ whatiscam/overview.htm. 2009.
$>_{11}$

Schumock GT, Pickard AS: Comparative effectiveness research: Relevance and applications to pharmacy. Am J Health Syst Pharm 2009;66:1278-1286.

12 Brinkhaus B, Witt CM, Jena S, Linde K, Streng A, Wagenpfeil S, et al: Acupuncture in patients with chronic low back pain - a randomised controlled trial. Arch Intern Med 2006;166:450-457.

13 Witt CM, Jena S, Selim D, Brinkhaus B, Reinhold $\mathrm{T}$, Wruck K, et al: Pragmatic randomized trial of effectiveness and cost-effectiveness of acupuncture for chronic low back pain. Am J Epidemiol 2006; 164:487-496. 